\title{
SHADE CHANGES OF CEMENTED CERASMART LAMINATE VENEERS AFTER EXPOSURE TO COM- MONLY CONSUMED BEVERAGES (AN IN VITRO STUDY)
}

\author{
Shaza M. Gendia*; Jylan F. ElGuindy ${ }^{* *}$ and Maha A. Taymour ${ }^{* * *}$
}

\begin{abstract}
Statement of the problem: Many types of ceramic laminate veneers are characterized by long term color instability. Soft drinks and beverages such as coffee and carbonated orange juice are the type of diet consumed by the larger populations; these beverages may affect the color stability of hybrid ceramic restorations. Purpose: The aim of this in vitro study was to evaluate the shade changes of bonded CERASMART laminate veneers after exposure to commonly consumed beverages (carbonated orange juice and coffee) compared to artificial saliva (control group) Materials and methods: a total of 36 freshly extracted anterior teeth were prepared with butt joint design to receive CERASMART laminate veneers. Laminate veneers were bonded using total etch protocol and RelyX veneer cement. All samples were subjected to thermo-cycling, then randomly divided according to the type of the immersion solutions into 3 groups, 12 samples in each group. Group1: (control group) artificial saliva, Group2: coffee, Group3: carbonated orange juice. The samples were immersed in solutions in an incubator at $37 \mathrm{oC}$ for 24 days. Color measurements were recorded using VITA Easyshade ${ }^{\circledR}$ Advance 4.0 device at two different intervals: before immersion of samples and after 24 days immersion of the samples. Color change calculated using the equation $\Delta \mathrm{E}=\left[\left(\Delta \mathrm{L}^{*}\right) 2+\left(\Delta \mathrm{a}^{*}\right) 2+\left(\Delta \mathrm{b}^{*}\right) 2\right]^{1 / 2}$. The data obtained were collected, tabulated and then subjected to statistical analysis. Results: A statistically significant difference was found between (Carbonated orange juice) solution on one hand and each of (Artificial saliva) and (Coffee) solutions groups on the other hand where $(\mathrm{p}=0.018)$ and $(\mathrm{p}=0.003)$ respectively. No statistically significant difference was found between (Artificial saliva) and (Coffee) solutions where ( $\mathrm{p}=0.653$ ). Coffee recorded statistically significant highest color change among all immersion solutions. All bonded CERASMART laminate veneers showed clinically unacceptable color difference $\Delta \mathrm{E}$ more than 3.3. Conclusions: it was concluded that CERASMART restorations suffer from remarkable color instability and it should be avoided in patients with high consuming frequency of coffee and carbonated beverages.
\end{abstract}

Keywords: laminate veneers, Hybrid ceramics, CERASMART, CADICAM, shade changes, beverages, Easyshade.

\section{INTRODUCTION}

Restoration of smile is one of the most challenging and esthetically satisfying services a prosthodontist can render to a patient. Introduction of laminate veneers in 1970s marked the beginning of modern cosmetic dentistry by combining the principles of aesthetics and tooth conservation. Dental porcelain is used in fabrication of laminate veneers because of its esthetic properties, durability, and biocompatibility. Innovative computer assisted design/ computer-assisted manufacturing (CAD/ CAM) technologies have introduced new systems for dental restorations. Its efficiency has been proven in both in vitro and in vivo studies.

A wide collection of ceramic materials available for $\mathrm{CAD} / \mathrm{CAM}$ technology ranging from relatively weak feldspathic ceramic and leucite glass ceramic to high strength lithium dislicate glass ceramic and zirconium oxide. Most recent a ceramic/polymer material has been introduced to the market for

* B.D.S, Faculty of Dentistry - Misr International University.

** Professor, Fixed Prosthodontics Department, Faculty of Oral and Dental Medicine, Cairo University.

*** Lecturer, Fixed Prosthodontics Department, Faculty of Oral and Dental Medicine, Cairo University. 
permanent $\mathrm{CAD} / \mathrm{CAM}$ fabricated restorations, So-called "hybrid ceramics" (1). The first available member of this CAD/CAM material group is Vita Enamic. So far, hybrid ceramic materials in dentistry are defined as: "a material consisting of a ceramic substructure infiltrated with a composite material. The new ceramic/polymer materials supposedly combine the positive aspects of both ceramics and composites with beneficial properties for patients. It is claimed that the dual network of a ceramic and polymer material provides less brittleness, excellent machinability, and edge stability ${ }^{(2)}$. CERASMART is a hybrid ceramic material consists of flexible nanoceramic matrix with flexural strength $238 \mathrm{MPa}^{(3)}$.

One of the problems that face laminate veneers is long term color stability. Discoloration of porcelain restoration may be endogenous or exogenous. Chemical instability of the material may lead to endogenous color change. The exogenous staining may occur due to the ability of the restoration to adsorb or absorb stains in the oral cavity which may be potentialized by surface conditions such as roughness ${ }^{(4)}$ Also, Studies have been undertaken to evaluate the color stability of composite restorations and it has been concluded that composite resins are unable to retain the color they possess at the time of insertion.

With the intent of increasing the amount of information about the properties of hybrid ceramics when used for laminate veneers, it is necessary to evaluate its discoloration potential. Soft drinks and beverage are the type of diet which is consumed by the larger populations. The aim of this invitro study was to evaluate the effect of coffee, carbonated orange juice compared to artificial saliva (control group) on the color change of bonded CERASMART laminate veneers over 24 days' time period which resembles 2 years of drinking coffee and carbonated orange juice ${ }^{(5)}$ using a Spectrophotometer (Easyshade).

\section{MATERIALS AND METHODS}

Teeth Selection: A total of 36 freshly extracted human upper anterior teeth (centrals) with an average similarity in shade, shape and size were selected to be used in this study. All teeth were mounted in epoxy resin blocks using a custommade cylindrical shaped holder.

Teeth preparation: Teeth preparations were done using the computer numerically controlled (CNC) milling machine. The labial reduction was $0.5 \mathrm{~mm}$ at the cervical third and $0.7 \mathrm{~mm}$ at the middle and incisal thirds. The cervical margin of the preparation was ended by a chamfer finish line. The teeth were prepared with a butt joint design of a $1.2 \mathrm{~mm}$ incisal reduction without palatal chamfer.

\section{Cerec CAD/CAM laminates veneers construction:}

A CAD/CAM system (Cerec software 4.4) was used for the fabrication of all samples. Milling was done with CEREC (MC XL) milling machine. The restorations were finished using GC Ultimate finishing and polishing kit.

\section{Cementation procedure:}

\section{Surface treatment of CERASMART laminate veneers:}

The internal fitting surfaces were treated by 5\% Hydrofluoric acid for 60 seconds then washed under running water, air dried then silane coupling agent was scrubbed on the fitting surface gently and air thinned for $1 \mathrm{~min}$ according to manufacturer's recommendation.

\section{Surface treatment of the prepared natural tooth:}

Total etch bonding protocol $35 \%$ phosphoric acid was applied for 15 seconds for enamel then rinsed under running water. Gentle air dryness was performed on the etched tooth. The prepared teeth were coated with 2 consecutive coats of the single bond adhesive.

1. Cementation: using the translucent shade of light cured Rely X veneer luting resin cement. 
2. Seating of the veneers: Each laminate was seated on its respective tooth with finger pressure, and excess cement was carefully removed from the margins after 10 seconds of preliminary light polymerization, and the restoration were then completely light polymerized for all aspects of the tooth for 30 seconds each. (Figure 1)

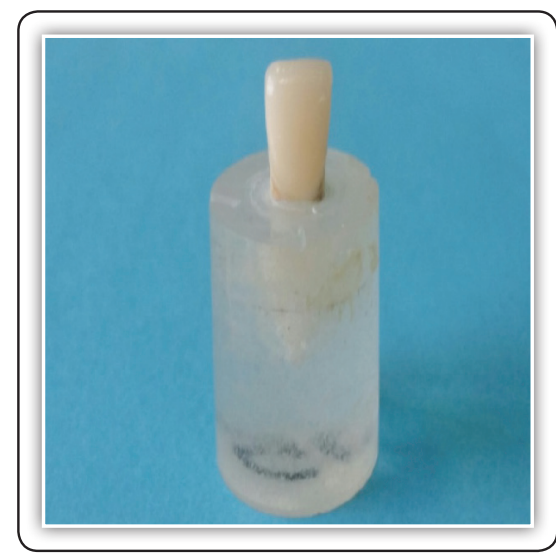

FIG (1) Bonded final restoration

\section{Thermocycling:}

In order to mimic the intra oral conditions the bonded specimens were subjected to thermocycling for 500 cycles with temperature changes between 5 $\mathrm{C}$ and $55 \mathrm{C}$ every 30 seconds.

\section{Randomization:}

All samples were allocated randomly. The samples were numbered from 1 and ascending to 36 , then were divided by www.random.org website into 3 groups equally.

- Group 1(control group): Includes 12 samples that were immersed in artificial saliva.

- Group 2: Includes 12 samples that were immersed in coffee.

- Group 3: Includes 12 samples that were immersed in carbonated orange juice.

\section{Storage:}

The $\mathrm{pH}$ value for the immersion solutions were measured by a $\mathrm{pH}$ meter, $\mathrm{pH}$ values were $6.9,5,2.8$ for artificial saliva, coffee and carbonated orange juice respectively. After immersion, all tightly sealed containers were stored in the incubator at $37^{\circ} \mathrm{C}$ for 24 days. ${ }^{(5)}$ The solutions were changed every 12 hours. After storage, the samples were rinsed with distilled water for $5 \mathrm{~min}$ and blotted dry with tissue paper before shade measurement.

\section{Color change $(\Delta \mathrm{E})$ measurement:}

VITA Easyshade ${ }^{\circledR}$ Advance 4.0 was used to measure the shade of the samples; the samples were placed on a white background and the color measurements were recorded. The shade of samples was measured 2 times: one before immersion in solutions and one after immersion in the solutions for 24 days. CIE Lab* is expressed by the L* coordinate representing color luminosity, varying from white to black, and the $\mathrm{a}^{*}$ and $\mathrm{b}^{*}$ coordinates representing the chromaticity of the color, with axes varying from green to red and blue to yellow, respectively. The means of the values obtained were calculated, and the $\mathrm{L}^{*}, \mathrm{a}^{*}$, and $\mathrm{b}^{*}$ parameters were determined.

The Color difference $\Delta \mathrm{E}$ between the color coordinates was obtained through Hunter equation: $\Delta \mathrm{E}=\left[\left(\Delta \mathrm{L}^{*}\right)^{2}+\left(\Delta \mathrm{a}^{*}\right)^{2}+\left(\Delta \mathrm{b}^{*}\right)^{2}\right]^{1 / 2}$. Value of $\Delta \mathrm{E}>3.3$ clinically not acceptable. ${ }^{(6)}$ Data were collected, tabulated and statistically analyzed.

\section{RESULTS}

\section{A. Relation between different solutions in $\Delta \mathbf{E}$ of bonded laminate veneers:}

a statistically significant difference was found between (Carbonated orange juice) solution on one hand and each of (Artificial saliva) and (Coffee) solutions groups on the other hand where $(\mathrm{p}=0.018)$ and $(\mathrm{p}=0.003)$ respectively. No statistically significant difference was found between (Artificial saliva) and (Coffee) solutions where $(\mathrm{p}=0.653)$. Color changes of all bonded CERASMART laminate veneers were clinically not acceptable $\Delta \mathrm{E}$ more than 3.3. (table 2, figure 2). 
TABLE (2) The mean, standard deviation (SD) values of $\Delta \mathrm{E}$ of different groups

\begin{tabular}{|c|c|c|c|c|}
\hline \multirow[b]{2}{*}{ Variables } & \multicolumn{2}{|c|}{$\mathbf{E} \boldsymbol{\Delta}$} & \multicolumn{2}{|c|}{ Confidence interval for mean $95 \%$} \\
\hline & Mean & SD & Lower bound & Upper bound \\
\hline Artificial saliva & $17.74^{\mathrm{a}}$ & 4.89 & 12.60 & 22.87 \\
\hline Coffee & $19.43^{\mathrm{a}}$ & 2.64 & 16.66 & 22.20 \\
\hline Carbonated orange juice & $11.81^{\mathrm{b}}$ & 1.23 & 10.52 & 13.10 \\
\hline p-value & & & & \\
\hline
\end{tabular}

Superscripts with different small letters indicate statistically significance difference within the same column.

*; significant $(p \leq 0.05) \quad n s ;$ non-significant $(p>0.05)$,

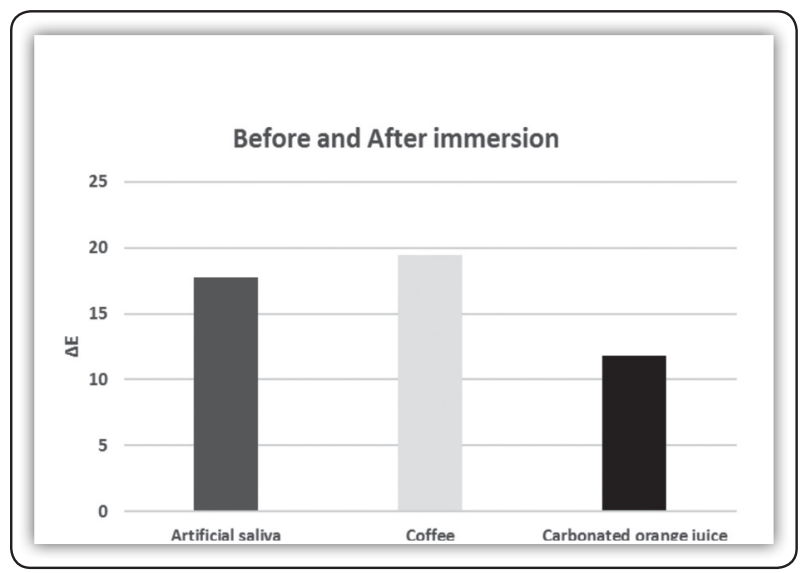

FIG (2) Bar chart representing effect of different solutions groups on $\Delta \mathrm{E}$

B. Effect of different solutions on $\Delta \mathrm{L}$ of bonded laminate veneers before and after immersion:

Color of all bonded CERASMART laminate veneers became darker after immersion in different solutions.

\section{Effect of different solutions on $\Delta \mathrm{a}$ before and after immersion:}

Color shifted toward greenness after immersion in artificial saliva, while color shifted toward redness in both coffee and carbonated orange juice groups.

\section{Effect of different solutions on $\Delta b$ before and after immersion:}

Color shifted toward yellowness after immersion in coffee, while color of samples immersed in both artificial saliva and carbonated orange juice shifted toward blueness.

\section{DISCUSSION}

Laminate veneers bonded to extracted teeth were used instead of dental ceramic specimens, as Kelly stated that the specimens used for testing dental ceramics in the lab sometimes differ significantly in both size and structure from the restoration they represent ${ }^{(7)}$. Polishing was performed for the laminate veneers regarding the evidence proving that stain resistance and color stability is improved with properly polished surfaces ${ }^{(8)}$. Translucent Rely X veneer cement (3M ESPSE) light cure adhesive resin was used as the amine accelerator necessary for dual cured polymerization can cause the color to change over time ${ }^{(9)}$.

The tested parameters were evaluated by immersion in coffee, carbonated orange juice and artificial saliva as a control. These solutions are the most commonly consumed beverage by the society and have different staining capabilities. Artificial saliva was chosen instead of human whole saliva to minimize the inter-individual variation in salivary protein content, and their instability extra-orally ${ }^{(10)}$.

Spectrophotometers have been proven to be a sophisticated color measuring device. VITA Easyshade ${ }^{\circledR}$ Advance 4.0 device is one of the most commonly used spectrophotometers available for clinical use ${ }^{(11)}$. The total immersion time was 24 days is equivalent to 2 years of consumption of the beverages. 
The storage media had a significant effect on the $\Delta \mathrm{E}$ of all groups. $\Delta \mathrm{E}=19.43$ for the samples stored in coffee, Ruyter et al ${ }^{(12)}$ showed that discoloration by coffee is due to adsorption and absorption of the pigments into the material. These findings are in correlation with previous studies performed by Nikzad et al ${ }^{(13)}$ for composite, and Jain et al ${ }^{(4)}$ for ceramic. This is however not in correlation with the study performed by Fontes et al ${ }^{(14)}$ who found no statistical color change for a nanofilled composite (Filtek 360) when stored in coffee. The reason for inconsistency might be different storage periods as they stored it for one week only.

Regarding samples within artificial saliva, there was statistically significance difference in $\Delta \mathrm{E}$. This may be attributed to that the staining susceptibility of ceramics is directly related to the degree of water sorption ${ }^{(5)}$. Carbonated orange juice caused a statistically significant color change $\Delta \mathrm{E}=$ 11.81. This could be due to yellow colorants, also the relatively low $\mathrm{pH}$ value of the solution causing a degree of degradation within the material ${ }^{(15)}$. Moreover, the results were not coinciding with the study performed by Nikzad et $\mathrm{al}^{(13)}$ where the material reached clinically unacceptable color changes after 2 weeks storage in acidic $\mathrm{pH}$ with a $\Delta \mathrm{E}$ reaching 6.48 but was 2.39 for porcelain.

All groups showed decreased lightness ( $\left.\mathrm{L}^{*}\right)$. This could be explained by the increase of water sorption which influences the refractive index of the material in case of artificial saliva. ${ }^{(16)}$ In accordance to Nikzad et al ${ }^{(13)}$ coffee caused the most decrease in the mean $\left(\mathrm{L}^{*}\right)$ when testing the color stability of indirect resin composites and feldspathic porcelain.

Regarding the parameter $\left(b^{*}\right)$, the coffee showed statistically highest increase in $\left(b^{*}\right)$, a shift to the yellow axis. This could be explained by the presence of the yellow colorants present in coffee thus increasing the yellow chroma of the sample. ${ }^{(17)}$ This is in accordance with Kumar et al in $2013^{(14)}$ who studied the color stability of feldspathic porcelain, after 45 days, coffee caused a gradual shift to the yellow axis. Carbonated orange juice showed statistically decrease in $\left(b^{*}\right)$, a shift to the blue axis, with the study performed by Nikzad et al in 2012(13) where specimens including indirect resin composite and feldspathic porcelain, turned yellower with coffee and bluer with cola.

\section{CONCLUSION}

Within the limitation of this study, the following conclusions were drawn:

1. Immersion of CERASMART bonded laminate veneers was drastically affected in terms of shade when immersed in coffee, carbonated orange juice and artificial saliva for 24 days, the shade changes were higher than the clinically acceptable threshold which is $\Delta \mathrm{E}=3.3$.

2. CERASMART restorations suffer from remarkable color instability according to our previous results so it should be avoided in patients with high consuming frequency of coffee and carbonated beverages.

\section{RECOMMENDATIONS}

Further studies are needed to evaluate the behavior of CERASMART in vivo. Since the role of saliva in diluting the $\mathrm{pH}$ value of the solutions was not considered, furthermore, the oral environment presents much more challenges and a much more complex environment, the continuous change in $\mathrm{pH}$ as well as different types of abrasive food, can affect the color of the restorations.

\section{REFERENCES}

1. El-Damanhoury H, Ali R and Platt J. Fracture Resistance and Microleakage of Endocrowns Utilizing Three CADCAM Blocks, Oper Dent. 2013; 1-10.

2. Spitznagel, F.A., Horvath, S.D., Guess, P.C., et al. Resin Bond to Indirect Composite and New Ceramic/Polymer Materials: A Review of the Literature. Journal of Esthetic and Restorative Dentistry 2014; 26(6), 382-393. 
3. Inc. G.A., CERASMART.

4. Kumar, P., Jain, C., Bhargava, A. et al. Spectrophotometric Evaluation of the Color Changes of Different Feldspathic Porcelains after Exposure to Commonly Consumed Beverages. European Journal of Dentistry 2013; 7(2), 172.

5. Arocha, M. A., Basilio, J., Llopis, J., et al. Colour stainability of indirect CAD-CAM processed composites vs conventionally laboratory processed composites after immersion in staining solutions. Journal of Dentistry 2014; 42(7), 831-838.

6. Feire A, and Archegas LR. Porcelain laminate veneer on a highly discolored tooth:a case report. Journal of Canadian Dental Association 2010; 76:126-7.

7. Kelly JR. Perspectives on strenght. Dent Mater 1995; 11(2):103-110.116.

8. Samra APB, Ribeiro DG, Borges CPF et al. influence of professional prophylaxis on reducing discoloration of different aesthetic restorative materials. J Dent. 2012; 40(452):71-76.

9. Cement, R. V. (n.d.). RelyX Veneer Cement Easy to use and provides excellent esthetic results .

10. Ionta FQ, Mendonca FL and De Oliveira GC. In vitro assessment of artificial saliva formulations on initial enamel erosion remineralization. J Dent. 2014; 42(2):175-179.
11. Knezović Zlatarić, D., Ileš, D., Alajbeg, I. et al. In Vivo and in Vitro Evaluations of Repeatability and Accuracy of VITA Easyshade ${ }^{\circledR}$ Advance 4.0 Dental Shade-Matching Device. Acta Stomatologica Croatica 2015; 49(2), 112-118

12. Um CM and Ruyter IE. Staining of resin-based veneering materials with coffee and tea. Quintessence Int. 1991; 22(5):377-386.

13. Nikzad S, Azari A and Poursina M. Effects of beverage colorants and accelerated aging on the color stability of indirect resin composites. J Dent Sci. 2012; 7(3):231-237.

14. Fontes, S. T., Fernández, M. R., de Moura, C. M., et al . S. Color stability of a nanofill composite: effect of different immersion media. Journal of Applied Oral Science: Revista FOB 2009; 17(5), 388-391.

15. Reddy PS, Tejaswi KLS, Shetty S, et al. Effects of commonly consumed beverages on surface roughness and color stability of the nano, microhybrid and hybrid composite resins: an in vitro study. J Contemp Dent Pract. 2013; 14(4):718 -723

16. Papadopoulos T, Sarafianou A, and Hatzikyriakos A. color stability of veneering composites after accelerated aging. Eur J Dent. 2010; 4(2):137-142.

17. Martos J, Osinaga PWR, Oliveria E De et al. Hydrolytic Degredation of Composite Resins: Effects on the Microhardness. Mater Res. 2003; 6(4):599-604. 